\title{
Visions of Computer Science - BCS International Academic Conference
}

\author{
Imperial College, London, UK \\ 22 - 24 September 2008
}

Editors:

Erol Gelenbe

Samson Abramsky

Vladimiro Sassone 


\section{Abstract}

The BCS launched its first international academic conference, intended as a major international event to take place in the UK. This year's theme was 'Visions of Computer Science'. Our aim was to establish the pattern of a high-quality wide-spectrum UK-based conference, with a strong international profile.

Moreover, to energise the UK community and bring it together around positive and inspiring visions of our discipline.

Keynote speakers included the following ACM Turing Award Winners: Fran Allen, Vint Cerf, Tony Hoare, Dick Karp, Robin Milner, Michael Rabin, Joseph Sifakis.

Invited speakers included Andrew Campbell - Dartmouth College, Steve Furber - The University of Manchester, Laurie Hendren - McGill University Canada, Nicholas Jennings - University of Southampton, Stephen Muggleton - Imperial College London, Brigitte Plateau - IMAG France, Moshe Vardi - RICE University Texas. 


\section{Full Synopsis}

Thoughts about a possible BCS academic conference germinated in the Summer and Autumn of 2007. There has been an ongoing discussion within the U.K. computing community for some time on how best to extend and strengthen learned society activities in computer science. The U.K. Computing Research Committee (UKCRC) had convened a working group on this topic, and one of the ideas that emerged from its discussions was of a conference, with the theme of Visions of Computer Science. We saw a conference around this theme as capable of playing an inspiring and formative role in the development of our discipline as a whole. Another major impetus came with one of us (EG) taking over as editor of the Computer Journal. Following this, and some congenial meetings at Imperial College hosted by EG, the ideas for this conference started to take shape. The relationship with the UKCRC Grand Challenge events was discussed, and the proposed conference was deemed to be both complementary to and supportive of these prior initiatives. A group that quickly became the programme committee took shape and held some meetings in London. After receiving the support of UKCRC, and the commitment of BCS support from Mike Rodd, we decided to take the risk of launching this conference with less that a year to go before it was to take place.

We all thought that this first conference must span a broad range of topics in computer science and engineering, going from theory to networks, from artificial intelligence and agents to digital systems, and from computer vision to programming languages and grand challenges. The next step of course was to mitigate the risk we were taking, including the preparation of a realistic and conservative budget that the BCS would find acceptable, and the identification of a viable date and venue.

However we also needed to mark our ambition with some exceptional speakers. Having contacted several Turing Award Winners, we were surprised and delighted by the support we received from Fran Allen, Vint Cerf, Tony Hoare, Dick Karp, Robin Milner, Michael Rabin and Joseph Sifakis, who all accepted the invitation. We are honoured by their trust and most grateful to them for their great contribution to making it a truly exceptional event. The programme committee also identified additional invited speakers who are outstanding leaders in their field, and we are most grateful to them too for making a major contribution to the programme.

Despite the conference's lack of a track record, the call for papers attracted a significant number of very good submissions, so that the first BCS 'Visions of Computer Science' is truly outstanding, and a special issue of the Computer Journal will include a selection of papers that are included in these proceedings.

Thus the programme of 'Visions of Computer Science' comprises seven keynote speakers, seven invited speakers, and 34 contributed papers, selected from 79 submissions. These were thoroughly peerreviewed by programme committee members and by several external reviewers. We find these figures rather promising for the future of a new conference being held for the very first time.

The call for papers solicited submissions in all areas of research covering the broad field of computer science and engineering, ranging from digital systems and computer architectures to theoretical computer science, from artificial intelligence and agents to networks and web computation, from programming languages and software engineering to medical applications. In fact, the conference received high-quality submissions in all of its areas of interest, and in the end several good papers unfortunately had to be excluded for lack of space. The accepted papers can be classified roughly as follows. 
Algorithms \& complexity: 4

Artificial intelligence: 3

Biocomputing: 2

Computer vision: 3

Digital systems \& hardware: 5

Formal methods \& semantics: 5

Machine learning: 2

Networks: 4

Software eng \& programming methods: 5

Grand challenges: 1

The last of these categories refers to the UK Computing Research Committee's initiative 'Grand Challenges for Computing Research' (www.ukcrc.org.uk/grand challenges), to which a special session of the conference was dedicated. A panel and discussion on the role of women in computing was also organised by Ursula Martin and Caroline Wardle.

Because of its breadth, and its idea of pulling together the best from a very broad spectrum, 'Visions of Computer Science' is indeed a unique conference. We hope that will prove to be the first of a successful series of meetings - the future will tell how successful it can be. From our viewpoint, it has been a privilege to be associated with this first edition; we believe we have put together a programme of outstanding quality to match the occasion.

As we conclude, we express our deep gratitude to the programme committee members, as well as the referees, for accepting to join us in this enjoyable and hopefully successful expedition. We are grateful to Steve Furber for his support, and also to Tony Hoare for his encouragement and for helping us in securing support from Microsoft to allow a larger number of students to participate in this event. Special thanks go to the BCS team led by Mike Rodd, with Elaine Boyes, Clare Blunt, Anna Duckworth and Christine Duma. We also thank Dr Moez Draief and Mrs Shahareen Hilmy for their kind help at Imperial College, and the Imperial team that handles conferences and events for their active participation.

Samson Abramsky, Erol Gelenbe, Vladimiro Sassone

August 2008 


\section{Organisers}

Keynote Speakers

Fran Allen

Vint Cerf

Tony Hoare

Richard Karp

Robin Milner

Michael Rabin

Joseph Sifakis

Invited Speakers

Andrew Campbell

Steve Furber

Laurie Hendren

Nick Jennings

Stephen Muggleton

Brigitte Plateau

Moshe Vardi

Conference Chair

Erol Gelenbe

Programme Chairs

Samson Abramsky

Vladimiro Sassone

Local Organisation

Moez Draief

Programme Committee

Christian Beckmann 


\author{
Peter Buneman \\ Muffy Calder \\ George Costantinides \\ Yiannis Demiris \\ Anthony Finkelstein \\ Erol Gelenbe \\ Wendy Hall \\ Jennifer Hallinan \\ David Hutchison \\ Alex Rogers \\ Iain Stewart \\ Martyn Thomas \\ Federico Turkheimer \\ Mike Wooldridge \\ External Reviewers \\ Harith Alani \\ Saleem Bhatti \\ Julian Bradfield \\ Geogios Chalkiadakis \\ James Cheney \\ Stefan Dantchev \\ John Darlington \\ Hugh Davis \\ Edith Elkind \\ Paul Ezhilchelvan \\ Alessandro Farinelli \\ Michelle Galea \\ Lester Gilbert
}




\author{
Simon Harper \\ Jane Hillston \\ Johnathan Ishmael \\ Michael Mackay \\ Angelos Marnerides \\ Dave Millard \\ Kieron O'Hara \\ Daniel Paulusma \\ Dimitrios Pezaros \\ Gopal Ramchurn \\ Utz Roedig \\ Murray Shanahan \\ Manolis Sifalakis \\ Steven Simpson \\ Paul Smith \\ Issam Souilah \\ Roy Sterritt \\ Stefan Szeider \\ Balint Takacs \\ Christof Teuscher \\ Martyn Thomas \\ Alexander Tiskin \\ Ioannis Vetsikas \\ Antony Waldock \\ Mark Weal \\ Su White
}




\section{Editors}

This conference was edited by:

Erol Gelenbe, Samson Abramsky and Vladimiro Sassone 


\section{Papers:}

\section{Session 1: Al and Semantic Web}

Subarthi Paul, Raj Jain, Jianli Pan \& Mic Bowman $\quad$ A Vision of the Next Generation Internet: A

Policy Oriented Perspective http://dx.doi.org/10.14236/ewic/VOCS2008.1

Andrzej W. Przybyszewski Brain-Like Approximate Reasoning

http://dx.doi.org/10.14236/ewic/VOCS2008.2

David Corsar \& Derek Sleeman Developing Knowledge-Based Systems using the Semantic Web http://dx.doi.org/10.14236/ewic/VOCS2008.3

Erik Wilde \& Martin Gaedke Web Engineering Revisited

http://dx.doi.org/10.14236/ewic/VOCS2008.4

Graham White Contexts for Human Action $\quad$ http://dx.doi.org/10.14236/ewic/VOCS2008.5

\section{Session 2: Automata and algorithms}

Stefan Dantchev Dynamic Neighbourhood Cellular Automata

http://dx.doi.org/10.14236/ewic/VOCS2008.6

Maxime Crochemore \& Ely Porat Computing a Longest Increasing Subsequence of Length $\mathrm{k}$ in

Time O(n log log k) http://dx.doi.org/10.14236/ewic/VOCS2008.7

Paul Cockshott, Andreas Koltes, John O'Donnell, Patrick Prosser \& Wim Vanderbauwhede A Hardware Relaxation Paradigm for Solving NP-Hard Problems

http://dx.doi.org/10.14236/ewic/VOCS2008.8

\section{Session 3: Medical and bioinformatics}

Martin Wojtczyk, Michael Marszalek, Alois Knoll, Rüdiger Heidemann, Klaus Joeris, Chun Zhang, Mark Burnett \& Tom Monica Automation of the Complete Sample Management in a Biotech Laboratory http://dx.doi.org/10.14236/ewic/VOCS2008.9 
Ross McFarlane \& Irina V. Biktasheva Beatbox - A Computer Simulation Environment for

Computational Biology of the Heart http://dx.doi.org/10.14236/ewic/VOCS2008.10

\section{Session 4: Logics and Foundations of Computation}

Glynn Winskel Events, Causality and Symmetry

http://dx.doi.org/10.14236/ewic/VOCS2008.11

Corina Cîrstea, Alexander Kurz, Dirk Pattinson, Lutz Schröder \& Yde Venema Modal Logics are

Coalgebraic http://dx.doi.org/10.14236/ewic/VOCS2008.12

\section{Session 5: Decentralised and Complex Systems}

Rocío Aldeco-Pérez \& Luc Moreau Provenance-Based Auditing of Private Data Use http://dx.doi.org/10.14236/ewic/VOCS2008.13

Gulay Oke \& Georgios Loukas Distributed Defence Against Denial of Service Attacks: A Practical View http://dx.doi.org/10.14236/ewic/VOCS2008.14

\section{Session 6: Computer Vision and Pattern Recognition}

Mark S. Nixon, Cem Direkoglu, Xin U. Liu \& David J. Hurley On Using Physical Analogies for Feature and Shape Extraction in Computer Vision $\quad$ http://dx.doi.org/10.14236/ewic/VOCS2008.15

Faraj Alhwarin, Chao Wang, Dannijela Ristic-Durrant \& Axel Gräser Improved SIFT-Features Matching for Object Recognition http://dx.doi.org/10.14236/ewic/VOCS2008.16

Zakia Hammal, Miriam Kunz, Martin Arguin \& Frédéric Gosselin Spontaneous Pain Expression Recognition in Video Sequences $\quad$ http://dx.doi.org/10.14236/ewic/VOCS2008.17

Dragoljub Pokrajac, Natasa Reljin, Nebojsa Pejcic \& Aleksandar Lazarevic Incremental Connectivity-Based Outlier Factor Algorithm http://dx.doi.org/10.14236/ewic/VOCS2008.18

Arnab Sinha \& Sumana Gupta Fast Estimation of Nonparametric Kernel Density Through PDDP, and its Application in Texture Synthesis http://dx.doi.org/10.14236/ewic/VOCS2008.34 


\section{Session 7: Foundations}

Arnold Beckmann \& Faron Moller On the Complexity of Parity Games

http://dx.doi.org/10.14236/ewic/VOCS2008.19

Steffen van Bakel Subject Reduction vs Intersection

http://dx.doi.org/10.14236/ewic/VOCS2008.20

Kohei Honda \& Nobuko YoshidaA Unified Theory of Program Logics: An Approach based on the nCalculus $\quad$ http://dx.doi.org/10.14236/ewic/VOCS2008.21

Peter D. Mosses Component-Based Description of Programming Languages http://dx.doi.org/10.14236/ewic/VOCS2008.22

Peter Van Roy Overcoming Software Fragility with Interacting Feedback Loops and Reversible Phase Transitions http://dx.doi.org/10.14236/ewic/VOCS2008.23

\section{Session 8: Computer Architecture and Digital Systems}

Ashish Darbari \& Bashir M. Al-Hashimi Hardware Dependability in the Presence of Soft Errors http://dx.doi.org/10.14236/ewic/VOCS2008.24

Qiang Liu, George A. Constantinides, Konstantinos Masselos \& Peter Y.K. Cheung Compiling Clike Languages to FPGA Hardware: Some Novel Approaches Targeting Data Memory Organisation http://dx.doi.org/10.14236/ewic/VOCS2008.25

Chadlia Jerad, Kamel Barkaoui \& Amel Grissa Touzi On the Use of Real-Time Maude for Architecture Description and Verification: A Case Study http://dx.doi.org/10.14236/ewic/VOCS2008.26

Andreas Fidjeland, Wayne Luk \& Stephen Muggleton A Customisable Multiprocessor for ApplicationOptimised Inductive Logic Programming http://dx.doi.org/10.14236/ewic/VOCS2008.27

Daniel Greenfield \& Simon Moore Implications of Electronics Technology Trends to Algorithm Design http://dx.doi.org/10.14236/ewic/VOCS2008.28

\section{Session 9: Networks}


Erol Gelenbe \& Edith C.H. Ngai Adaptive Random Re-Routing for Differentiated QoS in Sensor Networks http://dx.doi.org/10.14236/ewic/VOCS2008.29

Abdulhakim Ünlü \& Albert Levi Two-Tier, Location-Aware and Highly Resilient Key Predistribution

Scheme for Wireless Sensor Networks http://dx.doi.org/10.14236/ewic/VOCS2008.30

\section{Session 10: Programming Languages}

Jan Jürjens, Yijun Yu \& Andreas Bauer Tools for Traceable Security Verification http://dx.doi.org/10.14236/ewic/VOCS2008.31

Eric Bodden, Patrick Lam \& Laurie Hendren Object representatives: a uniform abstraction for pointer information http://dx.doi.org/10.14236/ewic/VOCS2008.32

\section{Session 11: Grand Challenges}

Susan Stepney, Samson Abramsky, Andy Adamatzky, Colin Johnson \& Jon Timmis Grand

Challenge 7: Journeys in Non-Classical Computation http://dx.doi.org/10.14236/ewic/VOCS2008.33 